\title{
Relationship of Menarche age with Anthropometric profiles
}

\author{
Mahuwaa Chaudhary ${ }^{1}$, Navita Pareek $^{2}$ and Kirti M. Tripathi ${ }^{3 *}$ \\ ${ }^{1}$ Ph.D. scholar, Chaudhary Charan Singh University, Meerut \\ ${ }^{2}$ Department, Home Science, Banasthali University, Rajasthan \\ ${ }^{3}$ Krishi Vigyan Kendra, Bulandshahr, SVPUA\&T, Meerut \\ *Email: kirtitripathi.dixit@gmail.com
}

\begin{abstract}
Menarche (first menstrual period) is the major component in the reproductive life of women. The beginning of the same determines the start up of natural reproduction process in the women's life. As this biological trait has an important cultural, social and epidemiological implication. Increasing attention has been recently devoted by scientists to understanding the causes of age variations in the timing of this event. The present cross-sectional study was designed to investigate the relation between anthropometric parameters among the adolescent girls and age at menarche. 120 school adolescent girls aged 11-14 years old were selected by purposive sampling. Anthropometric examination including height $(\mathrm{cm})$, weight $(\mathrm{kg}), \mathrm{BMI}\left(\mathrm{kg} / \mathrm{m}^{2}\right)$, percent body fat $(\% \mathrm{BF})$, body frame size (BFS), waisthip ratio (WHR) were measured and information on age of menarche were collected. The result showed the mean age of menarche was 12.58 . There were a significant correlation between age at menarche and weight, height, BMI, \%BF \& BFS. The significant correlation showed that the higher the BMI, the lower the age of menarche. The menarche age is experiencing a decreasing trend. BMI can be considered as key factor for early menarche. However, it must be recognized that such developments will be followed by overweight, obesity, which all require a constant supervision.
\end{abstract}

Keywords: Menarche, Mean Age, BMI, \%BF, BFS, WHR.

Paper Cited: Chaudhary, M., Pareek, N. and Tripathi, K.M. (2017). Relationship of Menarche age with Anthropometric profiles. South Asian Journal of Food Technology and Environment, 3(2): 554561 .

\section{Introduction}

Menarche (first menstrual period) and menopause (end of menstruation) are the two major components in the reproductive life of women. Since the interval between two events determines the natural reproductive period during which female can procreate. As these two biological traits have important cultural, social and epidemiological implications. Increasing attention has been recently devoted by scientists to understanding the causes of age variations in the timing of these events (Thomas et al., 2001). Studies shows earlier menarche is associated with attaining the critical weight more quickly. Conversely, a late menarche is associated with body weight growth that is slower prenatally, postnatal or both (Hardy et al., 2000, Akohoshi et al., 2002).

The landmark of pubertal events in girls is the onset of puberty, Peak Height Velocity (PHV) and menarche. Menarche is a rather late event in puberty and usually occurs after PHV is achieved (Hardy et al., 2000).
The menarche age is often investigated for various reasons it is the one of the major index of the menopause. There have been studies on role of height, weight and body structure on the menarche age, however there is a disagreement on the role of these factors. Pejhan et al., (2011) considered that some body fat is necessary in female adolescents and optimal weight is required for onset the menstruation.

Karaponou (2010) estimated that throughout most of the $20^{\text {th }}$ century the average age at menarche has been falling by around three months each decade. In the $19^{\text {th }}$ century the average age at menarche was between 17 and 18 years, by the 1990's this had dropped to between 12 and 13 year and now it is uncommon for girls as young as 8 to have menarche (Berenjy et al., 2008). According to Sachan (2012) and Bagga (2000) overall mean age at menarche was 12.84 years. Menstruation is considered a sign of sexual health during the adolescence and fertility age of women. Historically, it has been celebrated 
as the gift of puberty in many human societies. Puberty is the result of hormonal changes in the hypothalamus-pituitary-gonad axis. This axis is stimulated weakly by placental hormones in the female fetus and it leads to secretion of gonadotropin releasing hormone $(\mathrm{GnRH})$ in the neonatal period. This hormone decreases and remains minimal up to adolescence when the occurrence of first menstruation marks it rapid increase (Bayat et al., 2012).

The age at menarche (first menstruation) is clinically valuable, since it forms a basis for diagnosing delayed puberty and pathologic and hormonal disorders. The age of first menstruation is different among various ethnicities. In the United States, the average age at menarche has shifted from 12.75 to 12.54 years over a period of 25 years. The age at menarche is reportedly 12.9 years in Europe, 12.5-12.9 in different regions of India, and 13.3 years in Africa (Anderson et al., 2003, Bektas, 2008). Data showing later onset of menarche among girls of parents with lower educational level, which may be a menarche tends to be earlier with urbanization. Age of menarche is also affected by ethnicity, social class differences, number of siblings, and secular trends (Gharravi et al., 2008).

Higher subcutaneous fat level and BMI pre pubertal ages are associated with increased likelihood of early menarche (Pourarom et al., 2003). Menarche occurred earlier in girls who were taller girls and girls with more body fat have earlier menarche. Girls who were heavier at 7 year had earlier menarche, found delayed maturation among girls who were stunted during the preschool years. Higher BMI and longer sum of skin folds were strongly associated with earlier menarche (Gharravi et al., 2008, OnlandMoret et al., 2005). Firsch (1974) believes that in order to short menstruation girls need to achieve a minimum weight of $47.8 \mathrm{~kg}$ and more importantly, their body fat should amount to $23.7 \%$ (from 16\%) therefore, the puberty starts earlier in medium obese girls (with $20-30 \%$ overweight than normal) than in girls with normal weight, in contrast, girls with malnutrition will experience a delay in menstruation (Pejhan et al., 2011, Thomas et al., 2001, Frisch et al., 1974, Norgan et al., 1997). There is a vast amount of literature at a later age will eventually grow taller compared with women who reach their menarche at an earlier age (Onland-Moret et al., 2005).

The girls who achieved menarche earlier (between 9-11 years) showed the maximum mean body weight (46 kg) among the three age groups, being $5 \mathrm{~kg}$ more than the mean weight of the girls in ideal age group. The late menarche group of girls showed the least mean body weight $(37 \mathrm{~kg})$ which was about $4.5 \mathrm{~kg}$ less than that of the ideal group. A similar trend was observed for maximum mean body height $(154.84 \mathrm{~cm})$ which was shown by girls who attained early menarche (between 9-11 years). Minimum height was observed for the girls in the late menarche age group (Pejhan et al., 2011). Less extensive training or weight loss may result in anovulatory menstrual cycle, or a shortened luteal phase. These disruptions of reproductive ability are due to hypothalamic dysfunction, which is correlated with weight loss or excessive leanness. It is proposed that these associations are causal and that the high percentage of body fat (26-28\%) in the mature human female may influence the reproduction. (Akahoshi et al., 2002).

\section{Materials and Methods}

The study was conducted to assess the anthropometric measurements at age of menarche and to verify the association of age at menarche with anthropometric measurements in Indian conditions. All subjects were selected from Banasthali University campus, Tonk, Rajasthan for this cross- sectional study. A criterion for the selection of sample was purposive sampling. Menarche girls were studied from school side of Banasthali campus. The variables were the age of menarche which is reported by their own self. Other variables were height, weight, body mass index (BMI) classified in categories of percentile for menarche girls, because, the percentile indicates the relative position of the child's BMI number among children of the same sex and age. For children and teens, BMI age- and sex-specific percentiles are used for two reasons

- The amount of body fat changes with age.

- The amount of body fat differs between girls and boys. 
Relationship of Menarche age with Anthropometric profiles

\begin{tabular}{|l|l|}
\hline Weight Status Category & Percentile Range \\
\hline Underweight & Less than the 5th percentile \\
\hline Healthy weight & 5th percentile to less than the 85th percentile \\
\hline Overweight & 85th to less than the 95th percentile \\
\hline Obese & Equal to or greater than the 95th percentile \\
\hline
\end{tabular}

The relevant data were collected by measuring the height $(\mathrm{cm})$, weight $(\mathrm{kg})$, waist circumference, wrist circumference, hip circumference and calculation of Body Mass Index (BMI) $\mathrm{kg} / \mathrm{m}^{2}$, Body Frame Size (BFS), Waist-Hip ratio (WHR), Percent body fat. BMI was calculated by the formula [Weight $(\mathrm{kg}) /$ Height $(\mathrm{m})]^{2}$. Body fat percent is calculated by following sex specific prediction formula (Deurenberg et al., 1991), Adult body fat $\%=(1.20 \times \mathrm{BMI})+(0.23 \times \mathrm{Age})-$ $(10.8 \times$ gender $)-5.4$, where, female gender $=0$. Body frame size is calculated by formula, $\mathrm{R}=$ Height $(\mathrm{cm}) /$ Wrist circumference $(\mathrm{cm})$ by (source: Krause's Food, nutrition \& diet therapy, 2004). Waist hip ratio is calculated by formula, WHR = waist circumference $(\mathrm{cm}) /$ hip circumference $(\mathrm{cm})$ (Source: Stanley,
2005). Data were expressed as frequency, percentage, mean and standard deviation. The whole data were analyzed by using Pearson coefficient of correlation with the help of SPSS (16.0) software.

\section{Results and Discussion}

Respondent's mean menarche age: Based on the results obtained in Table 1 the mean menarche age was 12.58 years which is similar among high school students in most western countries such as 12.4, 12.6, and 12.5 respectively in Italy, United state and UK (Region et al., 2010., Freedman et al., 2002., Joinson et al., 2011). It was inferred from Fig. 1 , that menarche age of 12 years was commonly seen in most of the subjects.

Table 1: Mean and SD of menarche age and Anthropometric parameters of subjects

\begin{tabular}{|l|l|}
\hline Parameters & Menarche (Mean \pm SD) \\
\hline Age $(\mathrm{yr})$ & $12.58 \pm 0.99$ \\
\hline Height $(\mathrm{cm})$ & $154.69 \pm 5.93$ \\
\hline weight $(\mathrm{kg})$ & $52.24 \pm 8.30$ \\
\hline BMI $\left(\mathrm{kg} / \mathrm{m}^{2}\right)$ & $21.88 \pm 3.65$ \\
\hline Percent body fat & $23.76 \pm 4.28$ \\
\hline Body frame size & $10.25 \pm 0.52$ \\
\hline Waist-hip ratio & $0.77 \pm 0.05$ \\
\hline
\end{tabular}

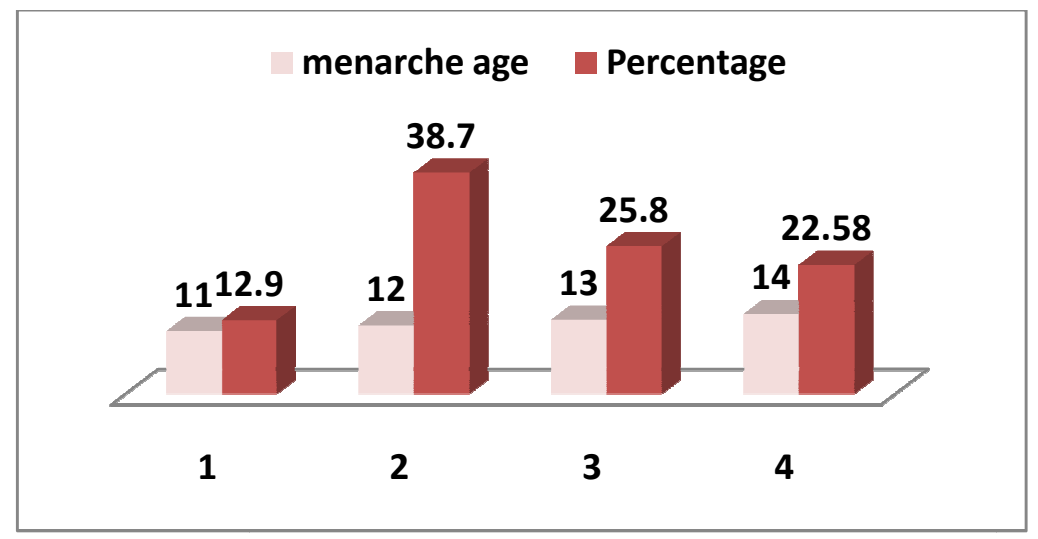

Fig. 1: Percentage distribution of menarche age of subjects 
Respondent's menarche age and height: Table 2 depicted that there was significant relationships between ages at menarche and the respondent's heights at the 0.05 level. It was shown that the maximum percentage of height $(45.8 \%)$ was from $151-155 \mathrm{~cm}$ and then only $6.6 \%$ girls reach to above $165 \mathrm{~cm}$ height. It revealed that the average height of menarche girls was $154 \mathrm{~cm}$. Fig. 2 scatter linear graph showed that the positive correlation between height and menarche age. Studies conducted by others showed that these students had earlier menarche and short adult height when compared to students who had menarche at a later age and taller height (Yeong et al., 2010, Gharravi et al., 2008, Okasha et al., 2001).

Table 2: Mean age at menarche and respondent's height $(\mathrm{cm})$

\begin{tabular}{|c|c|c|c|c|}
\hline Height(cm) & $n=120$ & Percentage & Mean \pm SD & \\
\hline$<150$ & 19 & 15.8 & $12.6 \pm 1.6$ & \multirow{5}{*}{$\begin{array}{l}\mathrm{r}=.312^{* *} \\
\mathrm{P}<0.05\end{array}$} \\
\hline $151-155$ & 55 & 45.8 & $12.1 \pm 1.57$ & \\
\hline $156-160$ & 27 & 22.5 & $12.5 \pm 1.03$ & \\
\hline $161-165$ & 11 & 9.1 & $14 \pm 0.47$ & \\
\hline$>165$ & 8 & 6.6 & $13.5 \pm 1.5$ & \\
\hline
\end{tabular}

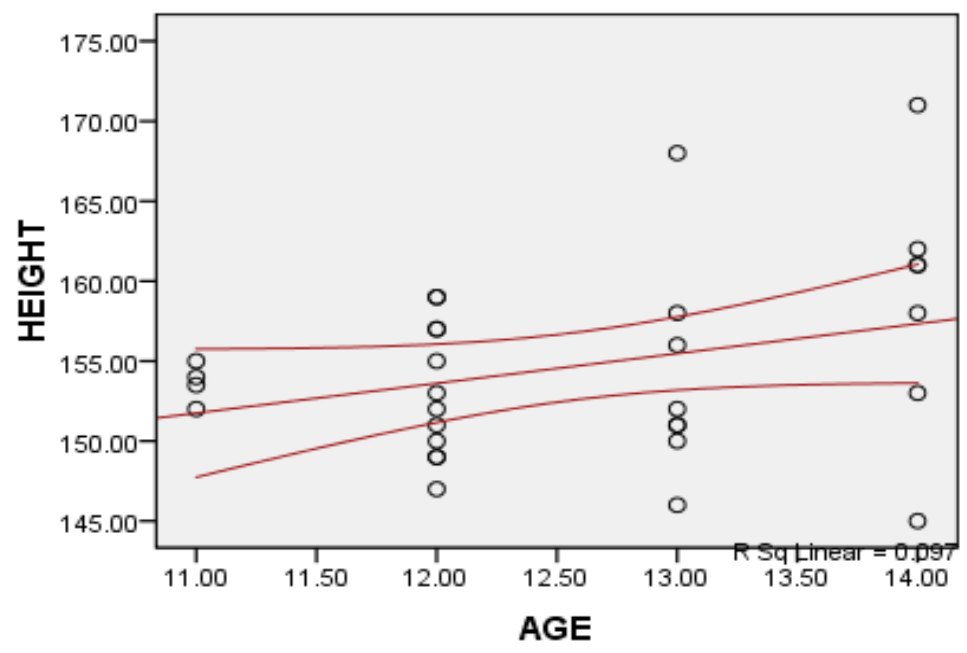

Relationship of height with menarche age

Fig. 2: Relationship of height with menarche age

Respondent's menarche age and weight: It is evident from Table 3 that there was significant correlation between ages at menarche and the respondent's weight at the 0.05 level. It was shown that the maximum percentage of weight
(46.6\%) was from 51-60 $\mathrm{kg}$ and then only $6.6 \%$ girls reached to above $71 \mathrm{~kg}$. It revealed that the average weight of menarche girls was $52 \mathrm{~kg}$. Fig. 3 scatter graph showed the negative correlation between weight and menarche age.

Table 3: Mean age at menarche and respondent's weight (kg)

\begin{tabular}{|l|l|l|l|l|}
\hline Weight (kg) & $\mathbf{n}=\mathbf{1 2 0}$ & Percentage & Mean \pm SD & \\
\hline$<40$ & 8 & 6.66 & $13 \pm 0$ & $\mathrm{r}=-.333^{* *}$ \\
\cline { 1 - 4 }$<1-50$ & 44 & 36.6 & $12.8 \pm 2.13$ & \\
\cline { 1 - 4 }$-61-60$ & 56 & 46.6 & $12.5 \pm 2.74$ & \\
\cline { 1 - 2 }-70 & 4 & 3.3 & $12 \pm 0$ & \\
\cline { 1 - 4 }$>71$ & 8 & 6.6 & $11.5 \pm 0$ & \\
\hline
\end{tabular}




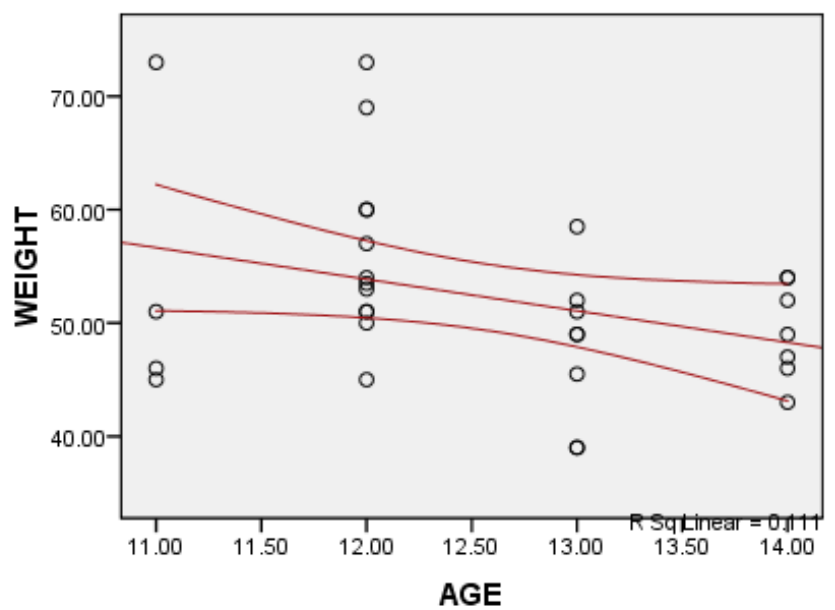

Fig. 3: Relationship of weight with menarche age

Respondent's menarche age and BMI: It revealed that the average BMI of menarche girls was between $5^{\text {th }}-85^{\text {th }}$ percentiles. Fig.4 scatter graph showed that the negative correlation between BMI and menarche age. Other studies stated that the greater the BMI, the lower the age of menarche (Pejhan et al.,
2011, Einy et al., 2006). Table 4 illustrated that there was significant correlation between ages at menarche and the respondent's BMI at the 0.05 level. It was shown that the maximum percentage of BMI $(58.06 \%)$ was from $5^{\text {th }}-$ $85^{\text {th }}$ percentile and then only $16.6 \%$ girl's reached to above $95^{\text {th }}$ percentile.

Table 4: Mean age at menarche and respondent's BMI $(\mathrm{kg} / \mathrm{m} 2)$

\begin{tabular}{|l|l|l|l|l|}
\hline BMI (percentile) & $\mathbf{n}=\mathbf{1 2 0}$ & Percentage & Mean \pm SD & \\
\hline$<5$ th & 0 & 0 & 0 & $\begin{array}{l}\mathrm{r}=-.449^{* *} \\
\mathrm{P}<0.05\end{array}$ \\
\cline { 1 - 4 } 5th -85 th & 70 & 58.3 & $13 \pm 0.97$ & \\
\hline 85th -95 th & 30 & 25 & $12.125 \pm 0.83$ & \\
\hline$>95$ th & 20 & 16.6 & $11.8 \pm 0.44$ & \\
\hline
\end{tabular}

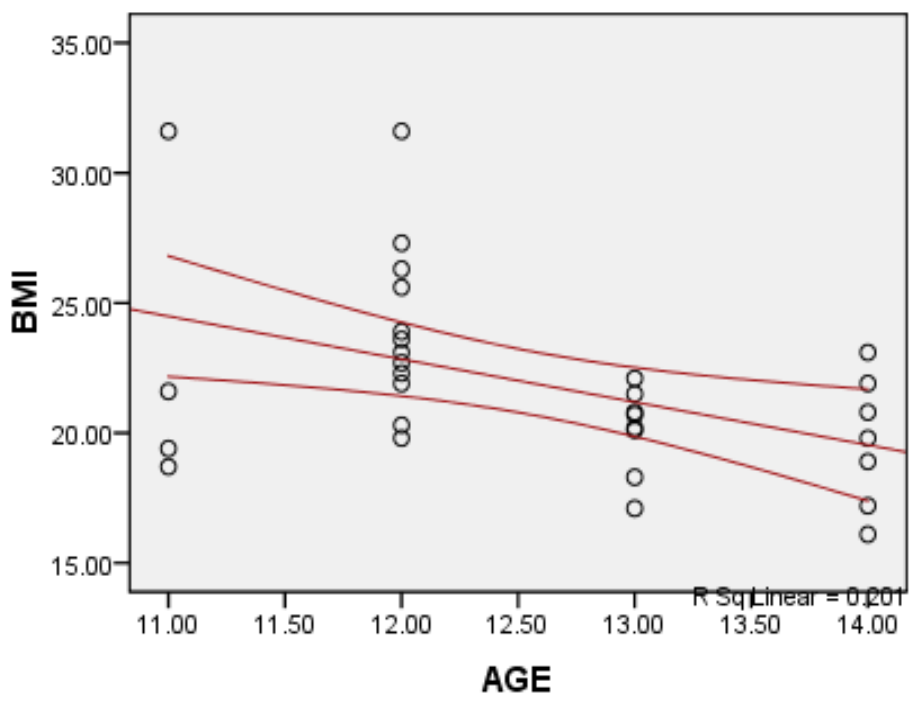

Fig.4: Relationship of BMl (percentile) with menarche age (yr) 
Respondent's menarche age and body fat: In Table 5, it is explained that there was significant correlation between ages at menarche and the respondent's percent body fat at the 0.05 level. It was shown that the maximum percentage of percent body fat (70 $\%$ ) was from $21-33 \%$ which was in healthy range and then only $6.6 \%$ girls reached to above $33-39 \%$ (overweight) and no one was in the obese category. It revealed that the average percent body fat of menarche girls was between $21-33 \%$. Fig.5 scatter graph showed the negative correlation between percent body fat and menarche age.

Table 5: Mean age at menarche and respondent's percent body fat

\begin{tabular}{|c|c|c|c|c|}
\hline Percent body fat & $n=120$ & Percentage & Mean \pm SD & \\
\hline$<21 \%$ & 28 & 23.3 & $13.1 \pm 1.24$ & \multirow{4}{*}{$\begin{array}{l}\mathrm{r}=-.405^{*} \\
\mathrm{P}<0.05\end{array}$} \\
\hline $21-33 \%$ & 84 & 70 & $12.5 \pm 2.44$ & \\
\hline $33-39 \%$ & 8 & 6.6 & $11.5 \pm 0.14$ & \\
\hline$>39 \%$ & 0 & 0 & 0 & \\
\hline
\end{tabular}

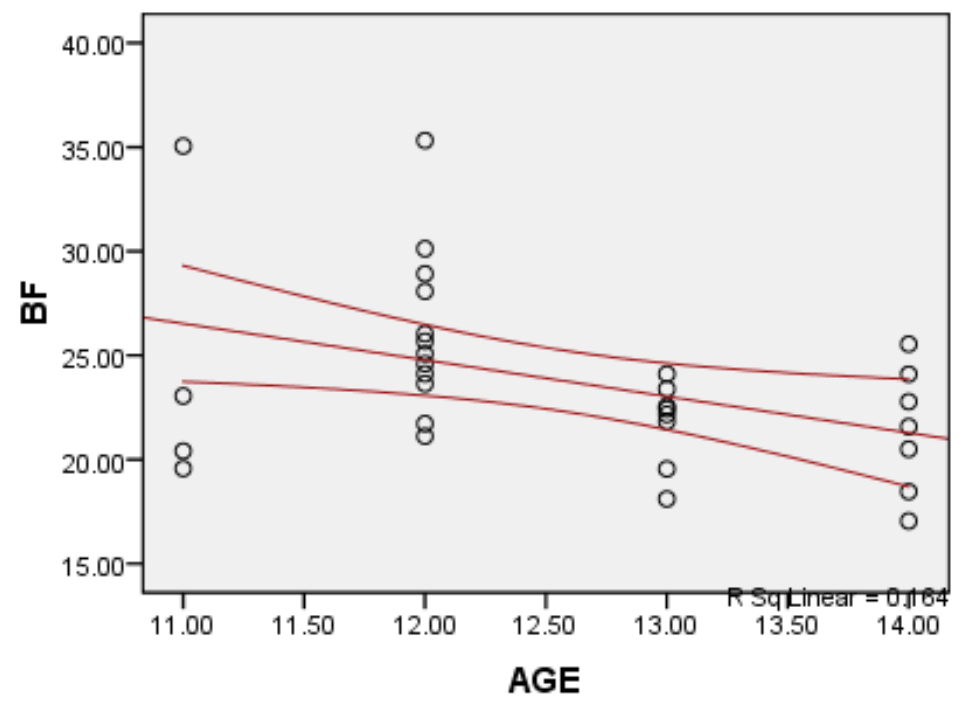

Fig. 5: Relationship of percent body fat with menarche age (yr)

Respondent's menarche age and BFS: Table 6 showed that there was no significant correlation between ages at menarche and the respondent's body frame size at the 0.05 level. It was shown that the maximum percentage of body frame size $(48.38 \%)$ was from $10.1-11.0$ which was under the medium frame size and then only $6.45 \%$ girls reached to above $>11.0 \%$ (small).

Table 6: Mean age at menarche and respondent's body frame size

\begin{tabular}{|l|l|l|l|l|}
\hline Body Frame Size & $\mathbf{n}=\mathbf{1 2 0}$ & Percentage & Mean \pm SD & \\
\hline$>11.0$ & 8 & 6.6 & $13.5 \pm 0.707$ & $\mathrm{r}=0.273$ \\
\cline { 1 - 4 } & $\mathrm{P}<0.05$ \\
\cline { 1 - 1 }$<10.1-11.0$ & 58 & 48.3 & $12.6 \pm 1.04$ & \\
\end{tabular}

Respondent's menarche age and waist-hip ratio: There was no significant correlation between ages at menarche and the respondent's Waist-hip ratio at the 0.05 level. It was shown that the maximum percentage of waist-hip ratio $(68 \%)$ was 0.8 which was in healthy range and then only $3.2 \%$ girls reached to above than normal. There was no correlation between waist to hip ratio and menarche age (Table 7). 
Table 7: Mean age at menarche and respondent's waist-hip ratio

\begin{tabular}{|c|c|c|c|c|}
\hline Waist-hip ratio & $n=120$ & Percentage & Mean \pm SD & \\
\hline 0.8 & 116 & 96.6 & $12.6 \pm 0.96$ & \multirow{2}{*}{$\begin{array}{l}\mathrm{r}=0.042 \\
\mathrm{P}<0.05\end{array}$} \\
\hline$>0.8$ & 4 & 3.3 & $12 \pm 0$ & \\
\hline
\end{tabular}

\section{Conclusion}

The mean age at menarche is decreasing continuously from 20 years in ethnic groups. Although the main timing of puberty changes is the genetic factors, other factors such as geographical location, general health status, nutrition and socioeconomic status affect the onset of menstruation and its progression. The present study concluded that there was a significant correlation between weight, height, BMI, body frame size, percent body fat and age at menarche, but there were no significant correlation found between waist-hip ratio and age at menarche. The negative correlation showed by linear graph with weight \& BMI stated that higher the weight and BMI, the lower the menarche age. Although BMI can be considered as key factor for menarche age, it must be recognized that such developments will be followed by overweight, obesity, which all require a constant supervision. Therefore, implementing educational plans to enhance the knowledge of the adolescent girls on their habits of nutrition and providing them with appropriate eating patterns is recommended, to change their lifestyle, so that implications resulting from lowered menarche age (such as preterm labor, sexually transmitted disease, cultural hassles, etc) are prevented to a large extent. Educational program implemented in schools can play a significant role in the preliminary prevention of nutritional disorders. The obesity problem in the adolescents may be solved through the cooperation of school officials, families and adolescents themselves.

\section{References}

1. Akahoshi, M., Soda, M., Nakashima, E., Tominaga, T., Ichimaru, S., Seto, S. and Yano, K.(2002). The effect of body mass index on age at menopause. International Journal of Obesity, 26: 961-968.

2. Anderson, S.E., Dallal, G.E. and Must, A. (2003). Relative weight and race influence average age at menarche: results from two nationally representative surveys of US girls studied 25 years apart. Pediatrics, 111:844-50.

3. Bagga, A., and Kulkarni, S. (2000). Age at menarche and secular trend in Maharastrian (Indian) girls. Acta Biologica Szegediensis, 44: 53-57.

4. Bayat, P., Ganbhari, A., Khazaie, M., Ghorbani, R. and Amiri, S. (2012). Age at Menarche and Related Factors in Girls of Urban Areas of Markazi (Central) Province of Iran. International Journal of Morphology, 30: 15-18.

5. Bektas, Y. (2008). Age at menarche in Ankara, Turkey. Anthropologiai Közlemények, 49:51-9.

6. Berenjy, S. and Hanachi, P. (2008). Relation of Obesity and Menarche Age among Adolescent Students. Journal of Family and Reproductive Health, 2: 173-177.

7. Deurenberg, P., Westatarte, J., and Seidell, J. (1991). Body mass index as a measure of body fatness: age- and sex specific prediction formulas. British Journal of Nutrition, 6: 105-114.

8. Einy, E., Mehrabi, U. and Azizi, F. (2006). Comparison of monarchial age between two generation of women (Tehran lipid and glucose study). Iranian Journal of Medical Sciences, 2: 35-40.

9. Freedman, D.S., Khan, L.K., Serdula, M.K., Dietz, W.H., Srinivasan, S.R., and Berenson, G.S. (2002). Relation of age at menarche to race, time period, and anthropometric dimensions: the Bogalusa Heart Study. Pediatrics, 110(4):43.

10. Frisch, R.E. and McArthur, J.E. (1974). Menstrual Cycles: Fatness as a determinant of minimum weight for height necessary for their maintenance or onset. Science, 185:949-951.

11. Gharravi, M.A., Gharravi, S., Marjani, A., Moradi, A. and Golalipour, J.M. (2008). Correlation of age at menarche 
and height in Iranian student girls living in gorgan - Northeast of Iran. Journal of the Pak Medical Association., 58: 426429.

12. Hardy, R.., Kuh, D. and Wadsworth, M. (2000). Smoking, body mass index, socioeconomic status and the menopausal transition in a British national cohort. International Journal of Epidemiology, 29: 845-851.

13. Joinson, C., Heron, J., Lewis, G., Croudace, T., and Araya, R. (2011). Timing of menarche and depressive symptoms in adolescent girls from a UK cohort. The British journal of psychiatry: The journal of Mental Science, 198(1):17-23.

14. Krause's (2004). Food Nutrition \& Diet Therapy ( $11^{\text {th }}$ Ed.), Eleviser (USA).

15. Norgan, N.G. (1997). The beneficial effects of body fat and adipose tissue in humans. International Journal of Obesity, 21: 738-746.

16. Okasha, M., McCarron, P., McEwen, J. and Smith, G.D. (2001). Age at menarche: secular trends and association with adult anthropometric measures. Annals of Human Biology., 28: 68-78.

17. Onland-Moret, N.C., Peeters, P.H., Van Gils, C.H., Clavel-Chapelon, F., Key, T., Tjønneland, A., Trichopoulou, A., Kaaks, R., Manjer, J., Panico, S., Palli, D., Tehard, B., Stoikidou, M., BuenoDe-Mesquita, H.B., Boeing, H., Overvad, K., Lenner, P., Quirós, J.R., Chirlaque, M.D., Miller, A.B., Khaw, K.T. and Riboli. E. (2005). Age at menarche in relation to adult height: the EPIC study. American Journal of Epidemiology, 162: 623-632.

18. Pejhan, A., Moghaddam, Y.H. and Najjar, L. (2011). The relationship between menarche age and anthropometric indexes of girls in Sabzevar, Iran. World Applied Sciences Journal, 14: 1748-1753.

19. Pour Aram, H., Aminpour, A., Kalantari, N., Golestan, B., and Abtahi, M. (2003). To investigate the anthropometric indices weight, height, subcutaneous fat mass and body mass index in urban and rural high school students of Astaneh Ashrafieh in 1999-2000. Iranian Journal of Gilan Medical Sciences University, 47: 56-66.

20. Rigon, F., Bianchin, L., Bernasconi, S., Bona, G., Bozzola, M., Buzi, F., Cicognani, A., De Sanctis, C., De Sanctis, V., Radetti, G. (2010). Update on age at menarche in Italy: toward the leveling off of the secular trend. The Journal of adolescent health: official publication of the Society for Adolescent Medicine, 46(3): 238-244.

21. Sachan, B., Idris, M.Z., Jain, S., Kumari, R. and Singh. A. (2012). Age at menarche and menstrual problems among school-going adolescent girls of a North Indian district. Journal of Basic and Clinical Reproductive Sciences, 1:56-59.

22. Stanley, J. (2005). Anthropometry (Edited by: C. G. Nicholas MascieTaylor). University of Cambridge.

23. Thomas, F., Renaud, F. and Benefice, E., de Meeüs, T. and Guegan, J.F. (2001). International Variability of Age at Menarche and Menopause: Patterns and Main Determinants. Human Biology, 73: 271-290.

24. Yeong, J.I. and O.H. Hawan, et.al. 2010. The relation of menarcheal age to antropometric profiles in Korean girls. Journal of Korean Medical Science, 25: 1405-1410.

$\begin{array}{ll}\text { Received } & \text { :August, } 2017 \\ \text { Revised } & \text { :Sept., } 2017 \\ \text { Published } & \text { : Dec., } 2017\end{array}$

